\title{
Dimensional accuracy of master casts made by one-step versus two-step putty wash addition silicone impression techniques: An in vitro study
}

\author{
Ranjukta Sar Avhad ${ }^{1}$, Rajendra Avhad ${ }^{2 *}$ \\ ${ }^{1}$ Senior Lecturer, ${ }^{2}$ Assistant Professor and HOD, ${ }^{1-2}$ Dept. of Prosthodontics, ${ }^{1}$ Pandit Deendayal Upadhyay Dental College, Solapur, \\ Maharashtra, ${ }^{2}$ Dr. Vaishampayan Memorial Govt. Medical College, Solapur, Maharashtra, India \\ *Corresponding Author: Rajendra Avhad \\ Email: drrajendraavhad@gmail.com
}

\begin{abstract}
Dimensional accuracy when making impressions is crucial to the quality of fixed prosthodontic treatment, and the impression technique is a critical factor affecting this accuracy. The purpose of this study was to compare the dimensional accuracy of one-step putty wash and twostep putty wash impression techniques using commercially available addition silicone impression material. The accuracy was assessed by measuring intraabutment and interabutment dimensions on stone dies poured from impressions of the master model, by using Toolmaker's microscope.
\end{abstract}

Keywords: Addition silicone impression material, Toolmaker's microscope, Polyvinyl siloxane, Universal testing machine (UTM)

\section{Introduction}

Fabrication of a fixed prosthesis is an indirect technique, in which the prosthesis has to be fabricated in the laboratory and then it is tried and fitted in the oral cavity. For this purpose accurate replicas of the dental and dento alveolar structures are required. Making the accurate impression of a single tooth or the whole dentition is very vital in obtaining accurate working casts, and for the fabrication of prosthesis or restorations. Amongst all the available impression materials, Polyvinyl siloxane (PVS) impression materials are extremely popular because of their combination of excellent physical properties, handling characteristics and dimensional stability ${ }^{1}$. Several variations of impression techniques have been advocated for accurate reproduction. Putty wash impression technique has gained wide popularity because of its simplicity. ${ }^{2}$

Advantages of the one-step double mix technique over the two-step double mix technique include reduced chair side time and savings of impression material. A disadvantage is that there are occasional ledges at the junction of the putty and wash material ${ }^{3}$.An advantage of putty wash two-step impression technique over one-step technique is that the impression of the teeth can be captured with the wash material. Disadvantage of the putty wash twostep impression technique is distortion ${ }^{3}$.Ideally, wash material should cover the entire preparation for both the techniques. However, clinically it is not always possible to accomplish this procedure ${ }^{3}$.

Despite a number of studies on the accuracy of impressions as related to the impression materials and/or the impression techniques, controversies remain. This necessitates further research to evaluate the accuracy between one-step double mix and two-step double mix putty wash impression techniques when used in conjunction with polyvinyl siloxane impression material. So, in this study both techniques will be evaluated with respect to the dimensional accuracy as a parameter.

\section{Materials and Methods}

Attempts were made to standardize the machinery and the procedures throughout the study to minimize the effect of variables on the observations and the result.

\section{Fabrication of Brass Model}

A mandibular arch, dentate silicone mould including third molars was poured with type IV die stone to obtain a cast. Tooth no. 46 was reduced on the retrieved cast to the gingival level to obtain a well-rounded edentulous ridge.

Teeth nos. 47, 45, 36 were prepared as if to receive full coverage cast crowns. Vertical grooves were placed on the buccal, lingual, mesial and distal aspects of 47, 45 and 36 using long straight fissure diamond point. Occlusal pinpoint depressions were made on all the three prepared teeth in their central grooves. The model was later invested and cast into a brass model. (Fig. 1)

\section{Custom Tray Fabrication}

Three sheets of modeling wax having $1 \mathrm{~mm}$ thickness were adapted on the brass model. They provided uniform space of $3 \mathrm{~mm}$ for the elastomeric impression material. The brass model with adapted wax was duplicated with irreversible hydrocolloid impression material in which type III gypsum was poured. Two sheets of modeling wax was then adapted onto the duplicated model for the tray former fabrication. Duplicated model was then flasked and counter flasked using type II dental plaster. After 45 minutes, dewaxing was done. Now a mould with the uniform space of $2 \mathrm{~mm}$ was obtained for the fabrication of custom trays. Acrylic resin tray material was mixed with adequate quantity of monomer and the mix was packed into the mould after it reached dough stage. After complete setting of the tray material, mould was opened and the tray was recovered. Using this technique, 60 custom trays were fabricated with nearly identical dimensions. Handle was made for a single tray and was duplicated for each tray using putty index made on the handle of the master tray. The handle was attached in a horizontal direction so that it could be oriented to the 
retention device in one particular direction. Equal numbers of holes were drilled at nearly similar locations into these trays using round stainless steel bur no. 8 for the purpose of mechanical retention of the elastomeric impression material. The trays were submerged in water for 24 hours and later used for impression making.

\section{Fabrication of Tray Positioning Device}

Tray positioning assembly consisted of a stainless steel platform to stabilize the master model and a plate for holding the tray. The Platform was provided with three positioning rods which coincided with three holes in the tray holding plate. Thus the tray was positioned exactly over the master model with no movement in any other direction. To prevent any lateral movement of the tray, two vertical rods were positioned both along the handle and adjacent to the flanges of the tray. Vertical stops on the positioning rods allowed a $2.5 \mathrm{~mm}$ depth of impression material over the abutments on the master model. Impression was removed along the vertical rods after it was set. Thus any lateral stresses were avoided during removal of the impression. (Fig. 2,3)

\section{Spacer Fabrication}

Polycarbonate sheet of $0.5 \mathrm{~mm}$ thickness was adapted on the brass model using Easy- Vac, Gasket, Vacuuform machine which served as a spacer for light bodied material.

\section{Impression Making}

Tray adhesive (3M, ESPE, USA) was applied evenly on the trays 20 minutes prior to making the impression. The handle of the custom tray was stabilized on the tray holding plate. Master model on the platform was stabilized on the universal testing machine. Fig. 4. the impression material (Aquasil soft putty/ regular set: Dentsply, USA. and Aquasil light viscosity material: Dentsply, USA) was mixed according to the manufacturer's recommendations.

One-step putty wash impressions: Fig. 5.

Equal amounts of putty base and catalyst was hand mixed and loaded onto the perforated tray. Simultaneously, the light body impression material was injected over the abutments with an automatic mixing syringe with a tip attached to it. Once the wash material was injected, the tray loaded with putty material was seated onto the abutments using tray positioning assembly and a constant pressure applied with a constant speed using UTM. The tray was held in place for 12 minutes for the material to set.

\section{Two- step putty wash impressions: Fig (6)}

Impression was made in the putty material with the polycarbonate spacer on the master model. The impression was allowed to set for 10 minutes. Once the impression was set, the spacer was removed and the light body material was injected over the abutments and tray was reseated over the master model accurately. The tray was held in place for 12 minutes for the material to set.
The impressions made by single-step double mix putty wash technique were considered as group $\mathbf{A}$ impressions. The impressions made by two-step double mix putty wash technique were considered as group $\mathbf{B}$ impressions.

The tray holding plate was positioned over the platform having brass model by coinciding vertical rods on the platform with the holes on the tray holding plate. After setting of the impression, platform and plate were separated along the vertical rods. All impressions were stored at room temperature $\left(25^{\circ} \mathrm{C}\right)$ for 1 hour before being poured. The type IV gypsum product (Karl rock) was vacuum mixed with distilled water following manufacturer's instructions, with a water/powder ratio of $10 \mathrm{ml} / 100 \mathrm{~g}$ and poured in the impression, which was held on the vibrator. Before pouring the impressions, they were sprayed with a debubblizer which reduces the surface tension of the elastomers and results in void free casts. The cast was retrieved from the impression after 40 minutes (as per manufacturer's instructions). All set impressions were removed from the master model with a single dislodging force along the positioning rods on the platform. Thus, lateral strains are avoided during impression removal. Thirty impressions were made using elastomeric impression material for both one-step and two-step techniques. The casts obtained from all these groups were labeled according to their group name. The casts were allowed to air dry for at least 48 hours before measurements were obtained and all the measurements were done by the same operator. All measurements from the master and stone models were made with a Toolmaker's microscope (Nikon, MM 400, Japan) ${ }^{4}$ capable of measuring up to $0.0001 \mathrm{~mm}$. Fig. 7.The distance between buccolingual grooves and mesiodistal grooves on 47 and the cross-arch dimension (occlusal pinpoint dimple of 47 to occlusal pinpoint dimple of 36) and the distance between the occlusal pinpoints dimples between 45 and 47 for were measured.

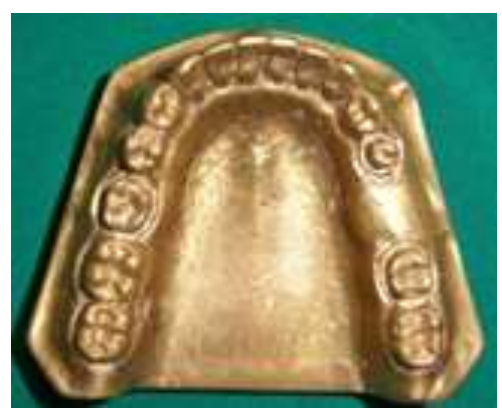

Fig.1: Brass model / master model

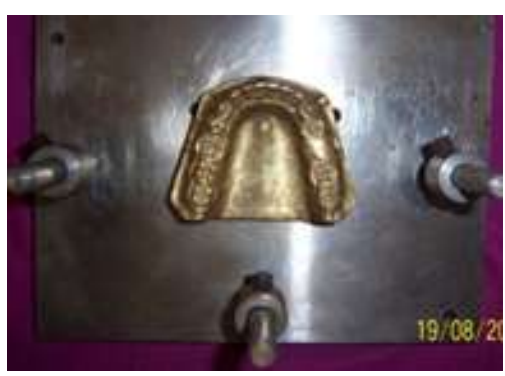

Fig.2: Master model fitted to the stainless steel platform 


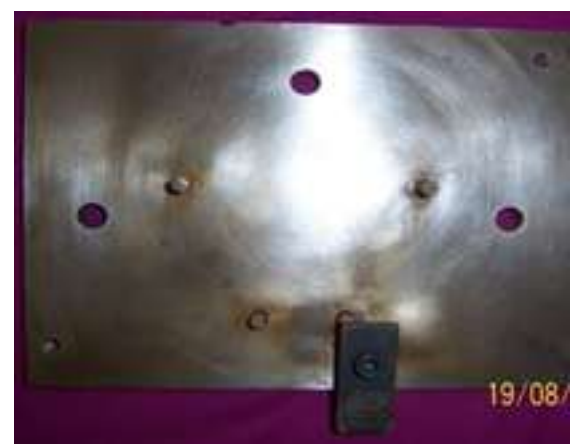

Fig.3: Custom tray positioning plate

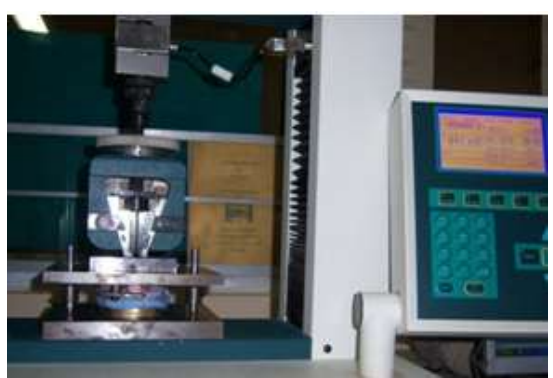

Fig.4: Impression made on universal testing machine

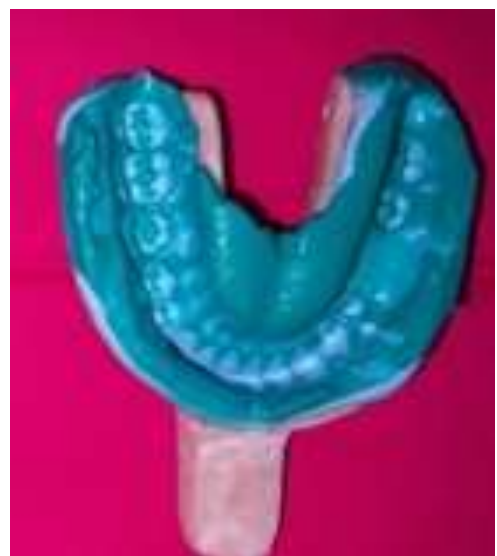

Fig.5: One-step putty wash impressions

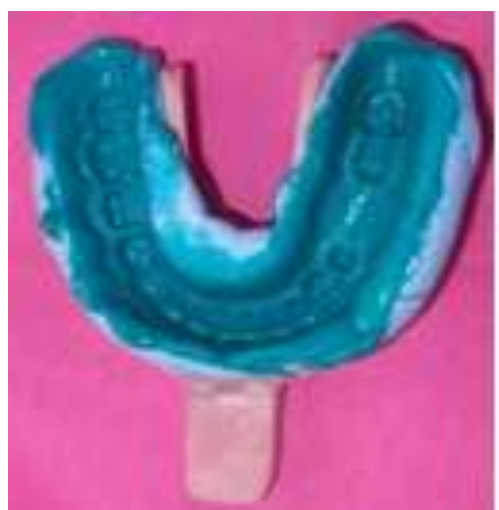

Fig.6: Two-step putty wash impressions.

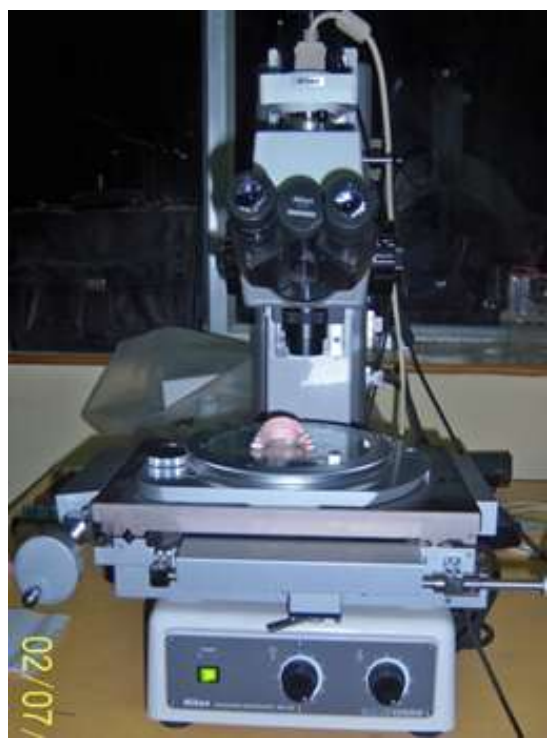

Fig.7: Toolmakers microscope

Table 1: mean and percentage (\%) of deviation from master model (MM) between groups A \& B

\begin{tabular}{|c|c|c|c|c|c|c|c|c|}
\hline \multirow[t]{2}{*}{$\begin{array}{c}\text { Type of } \\
\text { Measurement }\end{array}$} & \multirow[t]{2}{*}{ Group } & \multicolumn{2}{|c|}{ Distance MM } & \multirow[t]{2}{*}{$\begin{array}{l}\text { Deviation } \\
\text { from MM }\end{array}$} & \multicolumn{2}{|c|}{$\begin{array}{c}\% \text { of } \\
\text { Deviation }\end{array}$} & \multicolumn{2}{|c|}{$\begin{array}{c}\text { Level of } \\
\text { significance }\end{array}$} \\
\hline & & Mean & SD & & $\%$ & $\mu$ & t-value & P-value \\
\hline \multirow[t]{3}{*}{ Bucco lingual distance } & Master model(MM) & 5.6687 & & & & & & \\
\hline & Group A & 5.7356 & 0.011 & $0.066 \pm 0.011$ & 1.15 & 66 & -0.01 & 0.496 \\
\hline & Group B & 5.6915 & 0.009 & $0.022 \pm 0.009$ & 0.38 & 22 & 0 & 0.499 \\
\hline \multirow[t]{3}{*}{ Mesiodistal distance } & Master model(MM) & 7.1108 & & & & & & \\
\hline & Group A & 7.1853 & 0.012 & $0.074 \pm 0.012$ & 1.029 & 74 & -0.01 & 0.496 \\
\hline & Group B & 7.1446 & 0.006 & $0.033 \pm 0.006$ & 0.083 & 33 & 0 & 0.5 \\
\hline \multirow[t]{3}{*}{ Interabutment distance } & Master model(MM) & 18.2965 & & & & & & \\
\hline & Group A & 18.3737 & 0.011 & $0.077 \pm 0.011$ & 0.41 & 77 & 0 & 0.5 \\
\hline & Group B & 18.3160 & 0.005 & $0.019 \pm 0.005$ & 0.10 & 19 & 0 & 0.5 \\
\hline \multirow[t]{3}{*}{ Crossarch distance } & Master model(MM) & 45.8287 & & & & & & \\
\hline & Group A & 45.8928 & 0.008 & $0.064 \pm 0.008$ & 0.13 & 64 & 0 & 0.5 \\
\hline & Group B & 45.8474 & 0.009 & $0.018 \pm 0.009$ & 0.03 & 18 & 0 & 0.5 \\
\hline
\end{tabular}




\section{Results}

Each measurement was measured 3 times by the same operator. The mean was calculated, tabulated and statistically analyzed. Descriptive statistics like mean, standard deviation and percentage of standard deviation were calculated for each group .These observations were then statistically analyzed to determine level of confidence and significance to comparatively evaluate these values obtained. The values were subjected to student's unpaired ' $t$ ' test (used to find a statistical difference between two means). The comparison was made through the values of ' $p$ ' derived from the ' $t$ ' test. comparison was made between each technique and master model. A 'p' value of less than 0.05 was indicative of statistical significance and ' $p$ ' value of less than 0.01 was indicative of statistically highly significant.

The results showed that for group A-casts, the mean difference from the master model for buccolingual distance was $0.011 \mathrm{~mm}$, for mesiodistal distance was $0.0012 \mathrm{~mm}$, for interabutment distance was $0.011 \mathrm{~mm}$ and for cross arch distance was $0.008 \mathrm{~mm}$.

For group B casts, the mean difference from the master model for buccolingual distance was $0.009 \mathrm{~mm}$, for mesiodistal distance was $0.006 \mathrm{~mm}$, for interabutment distance was $0.005 \mathrm{~mm}$ and for cross arch distance was $0.009 \mathrm{~mm}$.

\section{Discussion}

Over the past four decades, tremendous progress has been made in procedures for making fixed prosthodontic impressions. These impression procedures continue to involve a wide range of techniques and an even wider range of materials.Various authors have reported conflicting results as regard to the superiority of one technique over the other. Fusiyama T. et $\mathrm{al}^{5}$ and Wassel R. et $\mathrm{al}^{6}$ reported that one step putty wash technique produced more accurate casts; whereas Chee W. et $\mathrm{al}^{2}$, Dhiman R. K. et $\mathrm{al}^{7}$, Johnson G. H. et $\mathrm{al}^{8}$ and Nissan J. et $\mathrm{al}^{4}$ reported that dimensional accuracy was better with two-step putty wash technique. However, Hung H. S. et $\mathrm{al}^{3}$, Idris B. etal ${ }^{9}$, Lacy A. M. et $\mathrm{al}^{10}$ and Stackhouse J. ${ }^{11}$ and Glen Johnson and Robert Craig ${ }^{12}$ did not find any difference between the two techniques.

The group A casts showed an increase in all distances which could be attributed to the polymerization shrinkage of the material towards the adhesive coated tray wall and because of setting expansion of die stone. In the one-step technique, the putty and wash materials are mixed and loaded simultaneously and are in contact with each other while the polymerization reaction is in progress. So the resultant shrinkage is the total polymerization shrinkage of putty and wash materials together. Impression material contracts towards the wall of the impression trays during polymerization. These results are in agreement with the findings of Idris B.et $\mathrm{al}^{13}$ and Nissan J.et $\mathrm{al}^{4}$ who showed an increase in interabutment distance when one-step putty wash technique was used. Another disadvantage of the one-step technique is that the margins may be duplicated in putty medium rather than lower viscosity materials which may result in inaccurate dies. ${ }^{1}$ It was also seen that the accuracy of the group A and group B casts were within the accepted range $(50 \mu \mathrm{m})^{14}$. However, group $B$ casts were closer to master model than group A casts in accuracy because of the uniform space provided for the wash material. So, the accuracy of two-step technique may be considered to be more than one-step technique ${ }^{1,7,8}$ but the differences were not clinically significant $(\mathrm{p} \geq 0.05)$.

Thus, either of the technique between one-step and twostep tested in the experiment may be recommended during the impression making procedure for the fixed partial denture. These results are in agreement with the findings of Hung H. S. et al, ${ }^{3}$ Nissan J. et al, ${ }^{4}$ Idris B. et al ${ }^{9}$, Johnson G. H. et al, ${ }^{12}$ Chee W. W. L. et al, ${ }^{1}$ James A. Stackhouse ${ }^{11}$.

\section{Conclusions}

Either one-step or two-step putty wash technique may be recommended for making the impressions of fixed partial denture prosthesis. Although this study demonstrates the use of either the one-step or two-step technique, it carries its limitations as in any in vitro study. Various clinical factors while making impressions should also be evaluated, such as the oral environment, presence of saliva, mouth temperature and so on. Further research is needed so that more elaborate conclusions can be drawn.

\section{Conflict of Interest: None.}

\section{References}

1. Chee W. W. L., T. E. Donovan. Polyvinyl siloxane impression materials: a review of properties and techniques. J Prosthet Dent 1992;68(5):728-32.

2. Chee W. W. L., T. E. Donovan. Fine detail reproduction of very high viscosity polyvinyl siloxane impression material. Int J Prosthodont 1989; 2(4):368-70.

3. Shirley H. Hung, John H. Purk, Daniel E. Tira \& David Eick. Accuracy of one-step versus two-step putty wash addition silicone impression technique. J Prosthet Dent 1992;67:583-9.

4. Nissan J., B. Z. Laufer, T. Brosh, D. Assif. Accuracy of the polyvinyl siloxane putty-wash impression technique. $J$ Prosthet Dent 2000; 83(10):161-165.

5. Fusiyama T., M. Iwaku, K. Daito, N. Kurosaki, T. Takatsu. Accuracy of laminated single impression technique with silicone materials. J Prosthet Dent 1974;32(3):270-76.

6. Wassel R. W., R. J. Ibbetson. The accuracy of polyvinyl siloxane impression made with standard and reinforced stock trays. J Prosthet Dent 1991;65(6):748-57.

7. Dhiman R. K., S. K. Agrawal, R. C. Dhir. Dimensional accuracy of putty-wash one-step and two-step techniques using polyvinyl siloxane impression material: in vitro study. $J$ Ind Prosthodontic Soc 2001;1(2):36-43.

8. Johnson G. H., D. G. Drennon. Clinical evaluation of detail reproduction of elastomeric impression materials. J Dent Res 1987;66:331.

9. Idris B., F. Houston, N. Claffey. Comparison of the dimensional accuracy of one and two step techniques with the use of putty/wash addition silicone impression materials. $J$ Prosthet Dent 1975;75(5):583-89.

10. Lacy A. M., H. Fukui, T. Bellman, M. D. Jendresen. Time dependent accuracy of elastomeric impression materials. Part II: polyether, polysulphide and polyvinyl siloxane. J Prosthet Dent 1981;45(3):329-33. 
11. James A. Stackhouse. The accuracy of stone dies made from rubber impression materials. J Prosthet Dent 1970;24(4): 37785.

12. Glen H. Johnson \& Robert G. Craig. Accuracy of addition silicones as a function of technique. J Prosthet Dent 1986;55(2):197-203.

13. Araujo P. A. D., K. D. Jorgensen. Effect of material bulk and undercuts on the accuracy of impression materials. J Prosthet Dent 1985;54(60:791-94.
14. Herbert T. Shillingburg, Sumiya Hobo, Lowell D. Whitsett, Richard Jacobi \& Susan E. Bracket. "Fundamentals of fixed prosthodontics". $3^{\text {rd }}$ ed. Quintessence publishing Co, Inc. 1997.

How to cite this article: Avhad RS, Avhad R. Dimensional accuracy of master casts made by one-step versus two-step putty wash addition silicone impression techniques: An in vitro study. Ann Prosthodont Restor Dent 2019;5(2):37-41. 